\title{
Psoriatic arthritis: genetics and pathogenesis
}

\author{
A. Cauli, A. Mathieu \\ A.O.U. Rheumatology Unit, Department of Medical Sciences, University of Cagliari, Italy
}

\begin{abstract}
SUMMARY
Psoriatic arthritis is a complex disease affecting primarily peripheral and axial joints and entheses together with the skin. The pathogenesis is characterized by a genetic background and by inflammatory mechanisms which may be triggered by environmental factors. Several susceptibility genes have been investigated; they include HLA genes, genes within the HLA region and genes outside the HLA region. T cells, including the recently described subset Th17, are thought to play an important role in the acute and chronic phases of the disease. Some of these findings allowed novel therapeutic interventions or opened new promising approaches in treatment. The most relevant data of the literature are summarized and discussed.
\end{abstract}

Key words: Psoriatic arthritis, genetics, pathogenesis, susceptibility, Th17, synovium, skin, enthesis

Reumatismo, 2012; 64 (2): 71-78

\section{GENETICS}

$\mathrm{T}$ The familial aggregation and inheritance of Psoriasis (Ps) and Psoriatic Arthritis (PsA) are typical of complex multigenic diseases. The risk to develop PsA in first-degree relatives of affected individuals is remarkably higher (30-40 times) compared to the general population; moreover, the risk for Ps and PsA is different in relatives of patients with the two diseases (1-5). The identification of susceptibility genes for PsA parallels that for Ps, and similarly to seronegative spondyloarthritis associated with inflammatory bowel diseases, also for PsA a dissection between the susceptibility genes for the cutaneous disease alone and for the arthritis has been attempted. PsA is characterized by the association of one of the different forms of Ps and one or more of the distinct clinical expressions of the arthritis; the genetic background of each of these clinical forms and expressions has been shown or is likely to be different, and it may explain the difficulty in assessing the genetic profile of the disease. In few cases, arthritis with typical signatures may not associate with cutaneous disease. Ritchlin (6) has clearly underlined the reasons which make difficult the analysis of genetic contribution to PsA development; possible confounding factors are:

1) the Linkage Disequilibrium (LD) possibly produced by a co-selection, in the same chromosome regions, of genes with different role in the susceptibility to the disease;

2) the difficulty to collect cases of disease not associated with Ps in order to study the genetic background of the articular disease alone;

3) the variety of topographic localization and clinical manifestations of PsA which seems to be associated with a number of genes related with the different disease expressions. If the pathogenetic pathways and the mechanisms of lesions are the same in Ps and PsA, it would be conceivable that they include both the genes of susceptibility to Ps and to PsA; however, there are several evidences, mentioned in the following paragraphs, supporting an alternative interpretation of the literature data (7).

As regards the cutaneous disease, type I Ps is characterized by an earlier onset (age $<40$ years) and by the association with the class I HLA-Cw6 allele (subtype Cw0602), while type II typically presents at an age $>40$ years and is not associated with Cw6 (8); the above association has been reported
Corresponding author: Prof. Alessandro Mathie Department of Medical Sciences Rheumatology Unit

A.O.U. University Clinic of Cagliari S.S 554, Monserrato - 09042 Cagliari, Italy E-mail: mathieu@medicina.unica.it 
about forthy years ago with both cutaneous and joint disease. HLA-Cw6 is the primary risk allele within the $300-\mathrm{kb}$ region, called PSORS1 (Psoriasis susceptibility gene 1), containing multiple candidate susceptibility genes. Other HLA and HLA-related genes (some in LD) have been shown to be associated with the disease, but there are evidences that polymorphisms, either in the same region of chromosome 6 harbouring Cw6, very close to it, or in different chromosomes, have been found to be associated with Ps. Similarly, genes harbouring outside of HLA region are also involved in the susceptibility to PsA (7). To date, the association with PSORS 1 appeared to be the strongest one among Ps patients, even if an association with PSORS 8 locus has been reported when the disease was present also in the father (8).

HLA locus B genes are highly polymorphic due to the evolutionary adaptation of the immune recognition and response to the variety and variability of environmen$\mathrm{tal} /$ microbial agents (9), and they have been found to be associated to PsA. Some of these genes appeared to be associated with PsA per se, while other have been found to be in LD with other polymorphisms primarily associated with the disease. This is the case of B16 with his splits B38 and B39, which are in LD with MICA-A9 gene, primarily associated with the symmetric polyarthritis form of PsA $(10,11)$. Another well known association involving a locus B gene is that between HLA-B27 allele and the axial form (spondilitis) of PsA. Several studies showed the association of B27 with radiographic sacroiliitis in PsA, especially when bilateral; moreover, the early onset of axial arthritis and Ps has been reported to be associated with the presence of HLA-B27, even if data in the literature is not concordant, and one study showed a more severe disease in patients carrying both B27 and DR7 (12-14). In other studies performed in three different series of patients no association has been found between PsA and alleles of B and C locus (15-17).

The polymorphic gene MICA (MHC class I chain related gene A) is located within the
HLA region close to B locus and TNF- $\alpha$ genes. It encodes for a stress inducible membrane glycoprotein, expressed on intestinal epitelial cells and in inflammed synovium, which acts as ligand for NKG2D expressed on NK and CD8+ T cells. In caucasian populations MICA-A9 has been reported to be an independent susceptibility gene for PsA $(10,11)$ with a gene dosing effect in conferring susceptibility to the symmetric polyarticular subset in overlap with axial involvement (18); however, one study showed a positive association with MICA-A4, while no association was reported with MICA-A9 (17).

In the HLA class I region, several other genes might play a role in susceptibility to Ps but especially to PsA: among them, the TNFo-238 polymorphism (8) and the SNP rs 1150735 . Very interesting results in order to dissect the genetic susceptibility to PsA from that to Ps come from some recent investigations $(19,20)$ and indicate that the TNF -857T allele is associated with susceptibility to PsA independently from the psoriasis susceptibility HLA-C0602 allele and PSORS1 locus. Other polymorphisms involved in susceptibility to Ps are those of TNF $\alpha$-induced protein 3 (TNAIP3) and TNFAIP3-interacting protein 1 (TNFAIPI), possibly participating to the pathway of NFkB (21).

A significant association with Ps has been reported for the genes encoding IL12B and $\operatorname{IL} 23 R(21,22)$; the products of these genes are involved in the Th17 and IL23 pathways. IL12B and IL23R polymorphisms have been shown to be associated primarily with type I Ps (similarly to Cw6), but it is seems that they are critical for the susceptibility of both the cutaneous and articular disease $(23,24)$, as suggested by the results of a clinical trial showing beneficial effects by neutralizing the cytokine pathway (25). Caspase recruitment domain-containing protein 15 (CARD15) function is to recognize bacterial molecules as the peptidoglycan muramil dipeptide, to interact with NFkB molecule and to elicit the immune response. The CARD15 gene polymorphisms have been found to be associated with some autoreactive diseases. When 
CARD 15 variants have been analyzed in two PsA series no relationship has been found $(15,26)$.

Other genes have been investigated with significant results: killer-cell immunoglobulin like receptor (KIR) genes and the deletion of LCE3C and LCE3B genes (encoding for the Late Cornified Envelope). The former ones encode membrane molecules which work as receptors for activating or inhibitory signals on NK cells. Interestingly, KIR genes seem to result in susceptibility when an imbalance in their products occurs $(27,28)$, while contrasting results have been reported for LCE3C and LCE3B genes, related with tissue permeability. Initially they have been found to associate with Ps (29) but not with PsA (30), although subsequently other authors have showed that LCE3C_LCE3B-del variant is a susceptibility factor also for PsA (31). Different association of susceptibility genes with single manifestations of the disease have been reported such as the lack of (or negative association of) $\mathrm{Cw} 6$ with onicopathy (32). An analogous absence of association with nail involvement has been reported for IL12B and IL23R by Filer et al.(24). This particular topic has been addressed by McGonagle et al. (33). According to Castelino and Barton (7), if Ps would not be necessary for the development of PsA, but is only a pathological condition superimposed to joint disease, the susceptibility genetic profile should be therefore only partially shared with PsA patients (29, $30,34)$. Due to the role of several ligands and receptors in regulating the innate and adaptive immune response through different pathways (35), quantitative expression of these genes is likely to be crucial factors for the phenotypic variety of the disease. Moreover, the possible role of variants of the previously mentioned TNFAIP3 gene in determining the response to TNFblocking treatment in Ps and PsA has also been investigated (36). A review of the association of genetic polymorphisms with therapeutic response to conventional and biotechnological treatment in Ps and PsA has been recently provided by O'Rielly and Rahman (37).

\section{PATHOGENESIS}

Although the pathogenesis of PsA remains unclear, intense research in the last decades has underlined the role of several immune cells, mediators and inflammatory pathways which play an important part in the mechanisms of disease pathogenesis. Imaging studies, in particular performed by means of MRI technology, have suggested that the enthesis, the site where tendons and ligaments attach to bone, may take an important active part in the early stages of disease. The close proximity of the enthesitis and synovitis in the PsA disease process has suggested that both site of inflammation may be considered as a functional single organ, the synovial/enthesal complex, source of proinflammatory mediators (38). The role of skin psoriasis, in relation to joint involvement, is also controversial and will be discussed in this review.

\section{The inflammatory milieu}

Several reports provide evidence that a $\mathrm{T}$ lymphocyte driven immune response is present in PsA. Both the skin and joints of patients with PsA show an inflammatory milieu characterized by a perivascular lymphocytic infiltrate of activated $T$ cells with signs of organ specific migration (39). These cells interact with antigen presenting dendritic cells (40) giving rise to the inflammatory cascade in the skin and joint compartments $(41,42)$. CD8+ T lymphocytes are the predominant cellular infiltrate in the epidermis, synovial fluid and enthesis, while CD4+ T cells are more abundant in the dermis and synovial membranes. In the synovial fluid the majority of $\mathrm{T}$ cells express the activation and memory markers HLA-DR and CD45RO (43). Oligoclonal expansions of $\mathrm{T}$ lymphocytes in synovial fluid and peripheral blood cells is also in support of a T cell antigen-driven response $(44,45)$. Furthermore, the effectiveness of $\mathrm{T}$ cell targeted therapy on psoriasis and PsA, with a more brilliant effect in the skin compartment, provide support to the primary role of $\mathrm{T}$ cell in disease pathogenesis. Synovial tissue analysis reveal that B lymphocytes forming primitive germinal cent- 
ers are also present in patients with PsA $(42,46)$, similarly to rheumatoid arthritis (RA). These lymphocyte organization mimic the germinal centers of secondary lymphoid organs and this process is called ectopic lymphoid neogenesis. These structures may provide local production of autoantibodies in RA. The significance of this finding in the pathogenesis of PsA is still controversial given the classical inclusion of PsA in the seronegative group of arthritides because of the absence or low frequency of autoantibodies (e.g. rheumatoid factor and anti-CCP) found in PsA patients. It is noteworthy that there is no correlation between the presence and degree of the aggregates and the clinical features of PsA (46).

Comparison of synovial membrane from PsA and RA patients has generally shown an higher degree of vascularisation but fewer macrophages in PsA $(41,47)$. A recent report has shown a similar pattern of fibroblasts and macrophages and, surprisingly, cytokines and matrix metalloproteinases did not showed significant differences. Interestingly, the number of infiltrating $T$ cell was the only clear difference observed, with PsA synovial membrane having less than half the number of synovial CD3 positive cells compared to RA tissue (48).

Apart from acquired immunity, recent studies point to an additional role of innate immunity in the inflammatory milieu of PsA by means of immunoglobulin-like receptors (KIR) expressed on natural killer (NK) cells. NK cells may express both inhibitory and/or activating KIRs, and it has been shown that KIR2DS1 and KIR2DS2 (activating ones) increases the susceptibility to develop PsA (49). A combination of innate immune signals by means of NK cells may even be the trigger of an inflammatory cascade that brakes the immune balance towards autoimmunity.

\section{IL-17, IL-23 and the Th17 subset}

PsA was classically considered a Th1-mediated disease, with IFN- $\gamma$ and IL-2 leading the orchestra of the inflammatory cascade. The discovery of IL-17 and the Th17 subset has substantially changed this paradigm.
Susceptibility to develop both skin psoriasis and PsA is associated with alleles of the $I L 12 B$ and IL23 receptor (IL23R) genes (50, 51). Furthermore IL23p19 and p40 (shared by IL-12p70 and IL-23 cytokines) sub-units, but not IL12p35 (only present in IL-12), are upregulated in lesional psoriatic skin compared to non-lesional skin (52). Moreover serum levels of IL12/23 p40 sub-unit are significantly higher in PsA patients compared to healthy controls (53). Given the importance of IL-23R and IL23 stimulation for the Th17 subset, all these data suggest a primary role of the Th17 subset in PsA.

The secretion of IL-17 by Th17 cells determines potent joint-destructive mechanisms by stimulating the production of IL-1 and TNF- $\alpha$ and by the induction of RANKL expression on mesenchymal cells (54). It is noteworthy that in anti TNF- $\alpha$ treated patients only responders show down-regulation of the IL-17 cytokine pathway, pointing to the concept that suppression of the Th17 subset is necessary for response to anti-TNF- $\alpha$ treatments (55). Furthermore IL-23 is able to induce osteoclastogenesis in the absence of RANKL and OPG, and antiIL-17 and anti TNF- $\alpha$ agents suppress IL-23 induced osteoclastogenesis (56). All these evidence, taken together, support the importance of the IL-23/IL-17 axis in the mechanisms leading to bone destruction. The beneficial effect of Th17 antagonism is well demonstrated by a randomised controlled trial in PsA patients which showed that treatment with human IL12/23 p40 monoclonal antibody is able to reduce the signs and symptoms of joint inflammation (25).

\section{Bone erosion and new bone formation}

Joint damage in PsA is characterized by bone erosions and new bone formation, and these alterations represent typical features of X-ray and MRI findings which helps physician in differential diagnosis. Bone erosions are driven by osteoclasts while new bone formation is due to osteoblasts activity.

Osteoclast precursors mature to functionally active osteoclasts following stimulation 
by several mediators or cells interaction, in particular macrophage colony stimulating factor and RANKL (soluble or membrane bound) binding to surface expressed RANK. Osteoprotegerin (OPG) modulate this interaction and balance osteoclast activity. Sub-condral bone and synovial tissue analysis in PsA patients demonstrate clear expression of RANK on perivascular mononuclear cells and osteoclasts. RAN$\mathrm{KL}$ is intensely expressed in the synovial lining cells while OPG expression is limited to vascular endothelial cells (57). This histological picture suggests that osteoclast precursors migrate to the inflamed synovium where they may be activated by RAN$\mathrm{KL}$ if unopposed by OPG. On this regard is noteworthy the observation that among the peripheral blood mononuclear cells from patients with PsA a large number of osteoclast precursors expressing TRAP (Tcell receptor activating protein are present) supporting the concept that osteoclasts detected in PsA synovium and bone are not only the local resident osteoclasts but also derive from precursors migration $(57,58)$. Futhermore, it has been shown that osteoclasts derived from CD 16+ cells present high erosive capability, and that increased CD16 cell expression is associated with increased bone erosion in PsA (59).

Although the role of TNF- $\alpha$ in PsA is broad and complex, it is worthwhile to underline that, in mouse models, TNF- $\alpha$ is able to increases the number of osteoclast precursors and that, in PsA patients, anti-TNF- $\alpha$ therapy significantly reduces their frequency. This evidence confirm that TNF- $\alpha$ plays an important role in the pathogenesis of the bone erosions in PsA. In summary, osteoclast precursors migrate to the joint and, if unopposed by OPG, interact with RANKL and TNF- $\alpha$ and differentiate in mature and functionally active osteoclasts (60).

Apart from bone erosions, new bone formation is also highly characteristic of PsA pathology and $\mathrm{X}$-ray findings. On this regard two main protein families have been described to play a critical role in the mechanisms which lead to bone remodeling; the wingless (Wnt) glycoprotein family and the Dickkopf-1 (DKK-1) protein family (61). The main function of DKK-1 is to antagonize the Wnt pathway by binding to the Wnt co-receptors LRP5 and Kremen- $1 / 2$, and therefore DKK-1 is considered a key protein in determining bone erosions. PsA patients present high levels of DKK-1 in serum as well as in the inflamed joint structures, and inflammatory cytokines such as TNF- $\alpha$ induce DKK-1 expression in the joints. Experimental evidence in animal models shows that blocking DKK-1 decreases the numbers of osteoclasts and increases osteophytes (62, 63). This observation may provide an explanation why TNF- $\alpha$ antagonisms in PsA patients does not seem to inhibit new bone formation (64).

\section{Animal models}

The best example of animal model of PsA is perhaps the knocked out JunB and C-Jun mice (65). Based on the rationale that JunB (part of the activator protein 1 transcription factor) is downregulated in psoriatic skin, Zenz et collaborators knocked out JunB and C-Jun genes in mice keratinocytes. These mice developed spontaneous psoriasis-like lesions and arthritis similar to PsA. It is noteworthy that when the JunB/C-Jun deleted mice were also unable to produce $\mathrm{B}$ and $\mathrm{T}$ cells, dermatitis was much milder in severity, synovitis was reduced and bone destruction was absent. A possible explanation for the observed immune reaction in the joint may involve cells directly exposed to the pathologic skin or resident cells of the joint exposed to higher circulating levels of soluble mediators derived from the skin. Although it is difficult to interpret all the findings in this animal model, the main message is that an event occurred in skin keratinocytes may determine an inflammatory reaction far away in peripheral joints, and that arthritis in these mice is $\mathrm{T}$ and $\mathrm{B}$ cell dependent and mediated by TNFR1.

\section{The complex interplay between the skin and the joint}

It is well known that in the majority of patients with PsA skin involvement precedes arthritis; moreover the Zenz et al. animal model suggest that arthritis may be second- 
ary and follow a psoriasis-like inflammatory skin disease. Although intriguing, the possibility that joint involvement in PsA patients may be caused by the release of mediators from the skin, still needs to be proven. In this skin-centric perspective the effect of even low levels of pro-inflammatory cytokines such as IL-1 may be to hypersensitize the synovium to endogenous ligands of the innate immune system. In other words an initial physiologic innate immune response associated with injury to the skin, or directly to the joint (66) may determine the initial trigger to the development of full blown PsA. It is fascinating to speculate that a chronic injury response could occur in the skin and then feed back to the synovium or the other way round.

In conclusion PsA is a very complex systemic immune mediated disease which affects susceptible subjects because of an unidentified trigger. The chicken or the egg causality dilemma may also apply to PsA and sounds like "which came first, the chicken (skin) or the egg (joint)?" Whatever the answer will be it is noteworthy that the clinical course of joint inflammation in PsA patients does not correlate with skin inflammation and viceversa, as evidence by a recent GRAPPA study, as if in the chronic stage they are two independent processes (67).

\section{REFERENCES}

1. Moll JM, Wright V. Familial occurrence of psoriatic arthritis. Ann Rheum Dis. 1973; 32: 181-201.

2. Myers A, Kay LJ, Lynch SA, Walker DJ. Recurrence risk for psoriasis and psoriatic arthritis within sibships. Rheumatology. 2005; 44: 773-6.

3. Pedersen OB, Svendsen AJ, Ejstrup L, Skytthe A, Junker P. On the heritability of psoriatic arthritis: disease concordance among monozygotic and dizygotic twins. Ann Rheum Dis. 2008; 67: 1417-21.

4. Chandran V, Schentag CT, Brockbank JE, Pellett FJ, Shanmugarajah S, Toloza SM, et al. Familial aggregation of psoriatic arthritis. Ann Rheum Dis. 2009; 68: 664-7.

5. Karason A, Love TJ, Gudbjornsson B. A strong heritability of psoriatic arthritis over four generations: the Reykjavik Psoriatic Arthritis Study. Rheumatology. 2009; 48: 1424-8.
6. Ritchlin CT. Pathogenesis of psoriatic arthritis. Curr Opin Rheumatol. 2005; 17: 406-12.

7. Castelino M, Barton A. Genetic susceptibility factors for psoriatic arthritis. Current Opinion in Rheumatology. 2010; 22: 152-6.

8. Duffin KC, Chandran V, Gladman DD, Krueger CC, Elder JF, Rahman P. Genetics of psoriasis and psoriatic arthritis: update and future directions. J Rheumatol. 2008; 35:1449-53.

9. Chandran V, Raychaudhuri SP. Geoepidemiology and environmental factors of psoriasis and psoriatic arthritis. J Autoimm. 2010; 34: 31421.

10. Gonzalez S, Brautbar C, Martinez-Borra J, LopezVazquez A, Segal R, Blanco-Gelaz MA et al. Polymorphismin MICA rather than HLA-B/C genes is associatedwith psoriatic arthritis in the Jewish population. Hum Immunol. 2001; 62: 632-8.

11. Gonzalez S, Martinez-Borra J, Lopez-Vazquez A, Garcia-Fernandez S, Torre-Alonso JC, Lopez-Larrea C. MICA rather tha MICB, TNFA, or HLA-DRB1 is associated with susceptibility to psoriatic arthritis. J Rheumatol. 2002; 29: 973-8.

12. Queiro R, Sarasqueta C, Belzunegui J, Gonzalez C, Figueroa M, Torre-Alonso JC. Psoriatic Spondyloarthropathy: A Comparative Study Between HLA-B27 Positive and HLA-B27 Negative Disease. Semin Arthritis Rheum. 2002; 31: 413-8.

13. Gladman DD, Anhorn KAB, Schachter RK, Mervart H. HLA antigens in psoriatic arthritis. J Rheumatol. 1986; 13: 586-92.

14. Gladman DD, Farewell VT. The role of HLA antigens as indicators of disease progression in psoriatic arthritis. Arthritis Rheum. 1995; 38: $845-50$

15. Rahman P, Bartlett S, Siannis F, Pellet FJ, Farewell VT, Peddle L, et al. CARD15: a pleiotropic autoimmune gene that confers susceptibility in psoriatic arthritis. Am J Hum Genet. 2003; 73: 677-81.

16. Queiro-Silva R, Torre-Alonso JC, TintureEguren T, Lopez-Lagunas I. The effect of HL-DR antigens on the susceptibility to, and clinical expression of psoriatic arthritis. Scand J Rheumatol, 2004; 33: 318-22.

17. Grubic Z, Peric P, Eeeuk-Jelicic E, Zunec R, Curkovic B, Kehrin-Brkljacic V. The MICAA4 triplet repeat polymorphism in the transmembrane region confers additional risk for development of psoriatic arthritis in the Croatian population. Eur J Immunogenet. 2004; 31: 93-8.

18. Mameli A, Cauli A, Taccari E, Scarpa R, Punzi L, Lapadula G, et al. Association of MICA alleles with psoriatic arthritis and its clinical forms. A multicenter Italian study. Clin Exp Rheumatol. 2008; 26: 649-52.

19. Reich K, Hoffmeier U, Konig IR, Lascorz J, Lohmann J, Wender J, et al. TNF Polym- 
rphisms in psoriasis: association of psoriatic arthritis with the promoter polymorphism TNF*-857 independento to the PSORS 1 risk allele. Arthritis Rheum, 2007; 56: 2056.

20. Giardina E, Huffmeier U, Ravindran J, Behrens $\mathrm{F}$, Lepre $\mathrm{T}$, McHugh $\mathrm{HJ}$, et al. Tumor necrosis factor promoter polymorphism $T N F^{*}-857$ is a risk allele for psoriatic arthritis independent of the PSORS1 locus. Arthritis Rheum . 2011; 63: 3801-6.

21. Nair RP, Duffin KC, Helms C, Ding J, Stuart PE, Goldgar D, et al. Genome-wide scan reveals association of psoriasis with IL-23 and NF-kappaB pathways. Nat Genet. 2009; 41: 199-204.

22. Cargill M Schrodi SJ, Chang M, Garcia VE, Brandon R, Callis KP, et al. A large-scale genetic association study confirms IL12B and leads to the identification of IL23R as psoriasisrisk genes. Am J Hum Genet. 2007; 80: 273-90.

23. Filer C, Ho P, Smith RL, Griffiths C, Young HS, Worthington J, et al. Investigation of association of the IL12B and IL23R genes with psoriatic arthritis. Arthritis Rheum 2008; 58: 3705-9.

24. Huffmeier U, Lascorz J, Bohm B, Lohmann J, Wendler J, Mossner R, et al. Genetic variants of the IL-23R pathway association with psoriatic arthritis and psoriasis vulgaris, but no specific risk factor for arthritis. J Invest Dermatol. 2009; 129: 355-8.

25. Gottlieb A, Menter A, Mendelsohn A, Shen YK, Li S, Guzzo C, et al. Ustekinumab, a human interleukin 12/23 monoclonal antibody, for psoriatic arthritis: randomised, doubleblind, placebo-controlled, crossover trial. Lancet 2009; 373: 633-40.

26. Giardina E, Novelli G, Costanzo A, Nisticò S, Bulli C, Sinibaldi C, et al. Psoriatic arthritis and CARD15 gene polymorphisms: no evidence for association in the Italian population . J Invest Dermatol, 2004; 122:1106-1107.

27. Martin MP, Nelson G, Lee JH, Pellett F, Gao $\mathrm{X}$, Wade J, et al. Cutting edge: susceptibility to psoriatic arthritis : influence of activating killer Ig-like receptor genes in the absence of specific HLA-C alleles. J Immunol. 2002; 169: 2818-22.

28. Nelson GW, Martin MP, Gladman D, Wade J, Trowsdale J, Carrington M. Cutting edge: heterozygote advantage in autoimmune disease : hierarchy of protection/susceptibility conferred by HLA and killer Ig-like receptor combinations in psoriatic arthritis. J Immunol. 2004; 173: 4273-6.

29. de Cid R, Riveira-Munoz E, Zeeuwen PL, Robarge J, Liao W, Dannhauser EN, et al. Deletion of the late cornified envelope LCE3B and LCE3C genes as a susceptibility factor for psoriasis. Nat Genet. 2009; 41: 211-5.

30. Huffmeier U, Estivill X, Riveira-Munoz E, Traupe H, Wendler J, Lohmann J et al. Dele- tion of LCE3C and LCE3B genes at PSORS4 does not contribute to susceptibility to psoriatic arthritis in German patients. Ann Rheum Dis. 2010; 69: 876-8

31. Docampo E, Giardina E, Riveira-Munoz E, de Cid R, Escaramis G, Perricone C, et al. Deletion of LCE3C and LCE3B is a susceptibility factor for psoriatic arthritis: a study in Spanish and Italian populations and meta-analysis. Arthritis Rheum. 2011; 63: 1860-5.

32. Fan X, Yang S, Sun LD, Liang YH, Gao M, Zhang KY, et al. Comparison of clinical features of HLACw0602 - positive and - negative psoriasis patients in a Han Chinese population. Acta Derm Venereol. 2007; 87: 335-40.

33. Mc Gonagle D, Benjamin M, Tan AL. The pathogenesis of psoriatic arthritis and associated nail disease: not associated after all? Curr Opin Rheumatol. 2009; 21: 340-7.

34. Zhang XJ, Huang W, Yang S, Sun LD, Zhang FY, Zhu QX, et al. Psoriasis genome-wide association study identifies susceptibility variants within LCE gene cluster at 1q21. Nat Genet. 2009; 41: 205-10.

35. Chatzikyrikidou A, Voulgari PV, Gergiou I, Drosos AA. The role of microRNA-146a (miR-146a) and its target IL-1R-associated kinase (IRAK1) in psoriatic arthritis susceptibility. Scand J Immunol. 2010, 71: 382-5.

36. Tejasvi T, Stuart PE, Chandran V, Voorhees JJ, Gladman DD, Rahman P, et al. TNFAIP3 gene polymorphisms are associated with response to TNF blockade in psoriasis. J Invest Dermatol. 2012; 132: 593-600.

37. O'Rielly DD, Rahman P. Genetics of susceptibility and treatment response in psoriatic arthritis. Nat Rev Rheumatol. 2011; 7: 716-32.

38. McGonagle D, Conaghan PG and Emery P. Psoriatic arthritis: a unified concept twenty years on. Arthritis Rheum. 1999; 42: 1080-6.

39. Pitzalis C, Cauli A, Pipitone N, Smith C, Barker J, Marchesoni A et al. Cutaneous Lymphocyte Antigen-positive T Lymphocytes Preferentially Migrate to the Skin but not to the Joint in Psoriatic Arthritis. Arthritis Rheum. 1996; 39: 137-45.

40. Cauli A, Pitzalis C, Yanni G, Hawad M, Panayi GS. CD1 positive antigen presenting cells in psoriatic and rheumatoid arthritis. Rheumatology 2000; 6:666-73.

41. Veale D, Yanni G, Rogers S, Barnes L, Bresnihan B, Fitzgerald O. Reduced synovial membrane macrophage numbers, ELAM-1 expression, and lining layer hyperplasia in psoriatic arthritis as compared with rheumatoid arthritis. Arthritis Rheum. 1993; 36: 893-900.

42. Veale DJ, Barnes L, Rogers S, Fitzgerald O. Immunohistochemical markers for arthritis in psoriasis. Ann Rheum Dis, 1994; 53: 450-4.

43. Costello P and FitzGerald O. Disease mechanisms in psoriasis and psoriatic arthritis. Curr Rheumatol Rep. 2001; 3: 419-27. 
44. Tassiulas I, Duncan SR, Centola M, Theofilopoulos AN, Boumpas DT. Clonal characteristics of $\mathrm{T}$ cell infiltrates in skin and synovium of patients with psoriatic arthritis. Hum Immunol. 1999; 60:479-91.

45. Costello PJ, Winchester RJ, Curran SA, Peterson KS, Kane DJ, Bresnihan B et al., Psoriatic arthritis joint fluids are characterized by CD8 and CD4 T cell clonal expansions appear antigen driven. J Immunol. 2001; 166: 2878-86.

46. Canete JD, Santiago B, Cantaert T, Sanmarti R, Palacin A, Celis R et al. Ectopic lymphoid neogenesis in psoriatic arthritis. Ann Rheum Dis. 2007; 66:720-6.

47. Yanni G, Whelan A, Feighery C, Fitzgerald O, Bresnihan B. Morphometric analysis of synovial membrane blood vessels in rheumatoid arthritis: associations with the immunohistologic features, synovial fluid cytokine levels and the clinical course. J Rheumatol. 1993; 20: 634-8.

48. van Kuijk AW, Reinders-Blankert P, Smeets TJ, Dijkmans BAC and Tak PP. Detailed analysis of the cell infiltrate and the expression of mediators of synovial inflammation and joint destruction in the synovium of patients with psoriatic arthritis: implications for treatment. Ann Rheum Dis. 2006; 65:1551-7.

49. Nelson GW, Martin MP, Gladman D, Wade J, Trowsdale $\mathrm{J}$ and Carrington M. Cutting edge: heterozygote advantage in autoimmune disease: hierarchy of protection/susceptibility conferred by HLA and killer Ig-like receptor combinations in psoriatic arthritis. J Immunol. 2004; 173: 4273-6.

50. Liu Y, Helms C, Liao W, Zaba LC, Duan S, Gardner $\mathrm{J}$ et al. A genome-wide association study of psoriasis and psoriatic arthritis identifies new disease loci. PLoS Genet. 2008; 4: e1000041.

51. Nair RP, Ruether A, Stuart PE, Jenisch S, Tejasvi T, Hiremagalore R et al. Polymorphisms of the IL12B and IL23R genes are associated with psoriasis. J Invest Dermatol. 2008; 128: 1653-61.

52. Lee E, Trepicchio WL, Oestreicher JL, Pittman D, Wang F, Chamian F et al. Increased expression of interleukin 23 p19 and p40 in lesional skin of patients with psoriasis vulgaris. J Exp Med 2004; 199: 125-30.

53. Szodoray P, Alex P, Chappell-Woodward CM, Madland TM, Knowlton N. Dozmorov I et al. Circulating cytokines in Norwegian patients with psoriatic arthritis determined by a multiplex cytokine array system. Rheumatology 2007; 46: 417-25.

54. Schett, G. and Teitelbaum SL. Osteoclasts and Arthritis. J Bone Miner Res. 2009: 24: 1142-6.

55. Zaba, LC, Suárez-Fariñas M, Fuentes-Duculan J, Nograles K, Guttman-Yassky E, Cardinale I et al. Effective treatment of psoriasis with etanercept is linked to suppression of
IL-17 signaling, not immediate response TNF genes. J Allergy Clin Immunol. 2009; 124: 1022-10. e1-395.

56. Yago T, Nanke Y, Kawamoto M, Furuya T, Kobashigawa T, Kamatani $\mathrm{N}$ et al. IL-23 induces human osteoclastogenesis via IL-17 in vitro, and anti-IL-23 antibody attenuates collagen-induced arthritis in rats. Arthritis Res Ther. 2007; 9: R96.

57. Ritchlin CT, Haas-Smith SA, Li P, Hicks DG, Schwarz EM. Mechanisms of TNF-alpha- and RANKL-mediated osteoclastogenesis and bone resorption in psoriatic arthritis. J Clin Invest. 2003; 111: 821-31.

58. Suda T, Takahashi N, Udagawa N, Jimi E, Gillespie MT, Martin TJ. Modulation of osteoclast differentiation and function by the new members of the tumor necrosis factor receptor and ligand families. Endocr Rev. 1999; 20: 345-57.

59. Chiu YG, Shao T, Feng C, Mensah KA, Thullen M, Edward M et al. CD16 (FcR gamma III) as a potential marker of osteoclast precursors in psoriatic arthritis. Arthritis Res Ther. 2010; 12: R14.

60. Lam J, Takeshita S, Barker JE, Kanagawa 0, Ross FP, Teitelbaum SL. TNF-alpha induces osteoclastogenesis by direct stimulation of macrophages exposed to permissive levels of RANK ligand. J Clin Invest. 2000; 106: 14818.

61. Schett G and Teitelbaum SL. Osteoclasts and Arthritis. J Bone Miner Res 2009; 24:11421146.

62. Morvan, F, Boulukos K, Clément-Lacroix P, Roman SR, Suc-Royer I, Vayssière B et al. Deletion of a single allele of the Dkk1 gene leads to an increase in bone formation and bone mass. J Bone Miner Res. 2006; 21: 934-45.

63. Diarra D, Stolina M, Polzer K, Zwerina J, Ominsky MS. et al. Dickkopf-1 is a master regulator of joint remodeling. Nat Med. 2007; 13: $156-63$.

64. Schett G, Stolina M, Dwyer D, Zack D, Uderhardt S, Krönke G. et al., Tumor necrosis factor alpha and RANKL blockade cannot halt bony spur formation in experimental inflammatory arthritis. Arthritis Rheum. 2009; 60: 2644-54.

65. Zenz R, Eferl R, Kenner L, Florin L, Hummerich L, Mehic D et al. Psoriasis-like skin disease and arthritis caused by inducible epidermal deletion of Jun proteins. Nature. 2005; 437: 369-75.

66. Punzi L, Pianon M, Rizzi E, Rossini P, Todesco S. Prevalence of post-traumatic psoriatic rheumatism. Presse Med. 1997; 26: 420.

67. Cauli A. Gladman DD. Mathieu A. Olivieri I. Porru G. Tak PP et al. GRAPPA 3PPsA Study Group. Patient global assessment in psoriatic arthritis: a multicenter GRAPPA and OMERACT study. J Rheumatol. . 2011; 38: 898-903. 